\title{
Atmospheric effects on the ultraviolet erythemal and total shortwave solar radiation in Valladolid, Spain
}

\section{Efectos de la atmósfera sobre la radiación solar eritemática y total de onda corta en Valladolid, España}

\author{
R. Román ${ }^{(1, *)}$, D. Mateos ${ }^{(1)}$, A. de Miguel( ${ }^{(1)}$, J. Bilbao( ${ }^{(1)}$, A. Pérez-Burgos ${ }^{(1)}$, \\ R. Rodrigo(2), V. E. Cachorro(2,S) \\ 1. Laboratorio de Atmósfera y Energía, Valladolid University, Po Prado de la Magdalena s/n, 47005, Valladolid, Spain. \\ 2. Grupo de Óptica Atmosférica, Valladolid University, Po Prado de la Magdalena s/n, 47005, Valladolid, Spain. \\ (") Email: robertor@fa1.uva.es S: miembro de SEDOPTICA / SEDOPTICA member \\ Recibido / Received: 30/01/2011. Aceptado / Accepted: 30/08/2011.
}

\begin{abstract}
:
Changes in erythemal and total shortwave due to variations in geometrical and atmospheric factors have been analyzed and quantified. The ozone, aerosol and water vapour effect on solar radiation has been obtained using radiation measurements at different fixed solar zenith angles. The results have showed a negligible effect of ozone on total shortwave radiation, and a stronger attenuation provided by aerosols in the erythemal case.
\end{abstract}

Keywords: Ultraviolet Erythemal Radiation, Ozone, Aerosols, Total Shortwave Radiation.

\section{RESUMEN:}

Se han analizado y cuantificado las variaciones en la radiación eritemática y total de onda corta provocadas por cambios en factores geométricos y atmosféricos. El efecto del ozono, aerosoles, y vapor de agua sobre la radiación solar ha sido obtenido mediante medidas radiométricas a diferentes ángulos cenitales fijos. Los resultados han mostrado que el efecto del ozono en la radiación total de onda corta es inapreciable, y que los aerosoles atenúan más a la radiación eritemática.

Palabras clave: Radiación Eritemática Ultravioleta, Ozono, Aerosoles, Radiación Total de Onda Corta.

\section{REFERENCIAS Y ENLACES / REFERENCES AND LINKS}

[1]. UNEP Assessment Reports: "Environmental effects of ozone depletion and its interactions with climate change: 2002 assessment", Photochem. Photobiol. Sci. 2, 1-72 (2003).

[2]. A. F. McKinlay, B. L. Diffey, "A reference action spectrum for ultraviolet induced erythema in human skin", Commission Internationale de l' Eclairage 6, 17-22 (1987).

[3]. WHO, Global Solar UV Index: A Practical Guide, pp 28 (2002).

[4]. A. de Miguel, R. Román, J. Bilbao, D. Mateos, "Evolution of erythemal and total shortwave solar radiation in Valladolid, Spain: Effects of atmospheric factors", J. Atmos. Terr. Phys. 73, 578-586 (2011).

[5]. M. J. Marín, A. R. Esteve, F. Tena, M. P. Utrillas, J. A. Martínez-Lozano, "UVI dependence on ozone amount and turbidity in Valencia", Opt. Pura Apl. 40, 25-30 (2007).

[6]. J. Bilbao, D. Mateos, A. de Miguel, "Analysis and cloudiness influence on UV total irradiation", Int. J. Climatol. 31, 451-460 (2011). 
[7]. WMO: "Scientific Assessment of Ozone Depletion: 2006, Global Ozone Research and Monitoring Project - Report No. 50. Geneva, Switzerland", 572 (2007).

[8]. D. Mateos, A. de Miguel, J. Bilbao, "Empirical models of UV total radiation and cloud effect study", Int. J. Climatol. 30, 1407-1415 (2010).

[9]. M. Antón, M. E. Koukouli, M. Kroon, R. D. McPeters, G. J. Labow, D. Balis, A. Serrano, "Global validation of empirically corrected EP-Total Ozone Mapping Spectrometer (TOMS) total ozone columns using Brewer and Dobson ground-based measurements", J. Geophys. Res. 115, D19305 (2010).

\section{Introduction}

The Sun emits radiation and a portion of this solar radiation reaches the Earth's surface crossing the atmosphere; it is called total shortwave (SW; $300-3,000 \mathrm{~nm}$ ). A range of solar radiation produces harmful effects on human beings [1]. It is the ultraviolet (UV) range and one effect is the erythemal production or sunburn on human skin, which can cause skin cancer in long time. The erythemal action spectrum was defined by [2] in order to quantify the effectiveness of UV radiation. The solar radiation weighted by the erythemal spectrum is called ultraviolet erythemal (UVER) radiation. The importance of UVER radiation was noted by [3].

Solar radiation reaching the surface is controlled by different factors such as solar geometry and atmospheric compounds. The geometry factors, so called astronomical factors, are the Earth-Sun distance (ESD), and the solar zenith angle (SZA) which depends on the coordinates of the place, the date and the hour. The influence of ESD is much lower than SZA, and the astronomical factors present annual cycle but no inter-annual variation. The atmospheric compounds that show the strongest influence on UV radiation are the ozone [4], the aerosols [5] and the clouds [6]. In addition, other gases control the radiation levels in the SW range at the ground, for example the water vapour.

An ozone depletion trend was observed in the last years [7], therefore the knowledge about the sensitivity of UVER with ozone changes radiation is important. Moreover, the changes in aerosol amount play an important role in control the UVER levels too.

The principal aim in this work is quantify the variation in UVER levels due to changes in factors such as SZA, ozone and aerosols. In addition, the SW variations are studied to complement the work. To this end, the influence of SZA, total ozone column (TOC), precipitable water column (PWC), and aerosol optical depth (AOD) on radiative fluxes are analyzed.

\section{Data gathering and method}

\section{2.a. Place, instrumentation and data}

The radiometric measurements were taken in the Solar Radiometric Station (SRS; 41 $40^{\prime} \mathrm{N}$; $4^{\circ} 50^{\prime} \mathrm{W}$ and $848 \mathrm{~m}$ above sea level) of the Valladolid University, Spain. The site is located in a rural area about $35 \mathrm{~km}$ NW from the city of Valladolid (Spain). UVER and SW broadband sensors were installed in this station, and the data provided by instruments were recorded by a micrologger Campbell CR23X every ten minutes as the average of ten seconds measurements. The final data-set were selected using a quality control criteria explained in [8].

UVER measurements were registered using a UVB-1 (Yankee Environmental Systems) pyranometer. This sensor provides UVER measurements using a matrix calibration. The matrix calibration depends on SZA and TOC and it is obtained using the spectral response of the sensor and a ground-measurements intercomparison with a spectroradiometer. The sensor is calibrated every year, and the last calibration was in September 2009 in the World Radiometric Center in Davos (Switzerland). The available 10-min UVER data ranges from June 2002 to December 2009, but some data were missing in 2006, 2007 and 2008 due to calibration activities and technical problems.

The pyranometer CM-6B (Kipp \& Zonen) was used to record the 10-min SW measurements. This sensor is calibrated every year using a reference, which was calibrated at the Spanish Institute of Renewable Energy (Ciemat). The last 
calibration of the reference was in 2009. The available SW irradiance data-set is longer than UVER one, ranging from November 2000 to December 2009.

Remote sensing measurements were used to obtain the daily TOC data. These data were provided until 2004 by "Earth Probe TOMS V8 corrected" algorithm, showing a deviation lower than 1\% [9], and the TOC before 2004 were provided by OMI sensor installed into Aura satellite. The uncertainties of OMI data derived from TOMS algorithm are below 3\%. The blank ozone data were completed using TOC values from GOME and GOME-2 satellite data.

Hourly AOD at $440 \mathrm{~nm}\left(\mathrm{AOD}_{440}\right)$ and PWC values have been used in this paper, and they were measured in AERONET-RIMA station of Palencia, a city close to Valladolid with similar atmospheric conditions. The data were measured using a CIMEL sunphotometer.

\section{2.b. Methodology}

The cloud effect must be removed to study the effect of other factors, therefore the final dataset were the values measured the days which sky was completely cloudless. The selection of cloudless days was applying two criteria: first, the days with a clearness index (expression 1) higher than 0.7, and the second criterion was a visual inspection. The first criterion passed 760 cloudless days, and finally the cloudless days were 350 . The clearness index, $k_{d}$, is defined as the ratio between the measured daily SW irradiation, $S W_{d}$ and the daily $\mathrm{SW}$ irradiation in the top of the atmosphere, $S W_{0 d}$ :

$$
k_{d}=\frac{S W_{d}}{S W_{0 d}} .
$$

In addition the cloudless data were normalized to the ESD of 1 AU. When the TOC, PWC and AOD effect was quantified, 10 different sub-datasets were selected for different fixed SZA with an error of $\pm 0.1^{\circ}$ to remove the dependence on SZA. Finally, the variation trend at a fixed SZA was calculated as the ratio between the slope of the linear fit and the mean value of the radiation analyzed. The feasibility of the trend was tested using the $95 \%$ confidence interval to see if the trend is statistically significant.

\section{Results}

The effect of SZA can be seen in Fig. 1 using the selected cloudless dataset. Figure 1 shows the linear dependence of SW irradiance on SZA cosine with a great determination coefficient; this dependence is mainly provided by the geometrical Sun position, because the measurements are registered in a horizontal surface. The deviation to the line fit is due to the uncertainties and the aerosol and other gases. However, UVER irradiance shows a good power behaviour due to the Sun position, but in addition due to the attenuation by the atmosphere and the dependence of the optical path with SZA. It means when SZA increases the UV photons cross more portion of atmosphere which implies more ozone absorption and Rayleigh scattering processes. In this case the deviation of the measured values to the line fit is due to the uncertainties and atmosphere composition too.

To observe the effect of atmosphere removing the SZA effect, ten subsets was chosen following the section 2.b criteria. Figure 2 shows the dependence on ozone of UVER and SW irradiance at different SZA. In SW irradiance the ozone effect is not significant and it cannot be appreciated because the strongest ozone absorption band is in the UV range, a little portion of SW radiation. On the other hand, in the UVER case, a linear correlation appears with the worst correlations for $\mathrm{SZA}>30^{\circ}$. The determination coefficients vary between 0.3 to 0.8 , being statistically significant for all SZA values. The decrease trend in percentage is close to the same value for all SZA values, and the average is $-0.31 \% \mathrm{DU}^{-1}$. Similar results were obtained in [4] using UVER monthly averages. Hence, the ozone effect can be removed by normalization to a standard value, 313 DU (average value in the region), through the next expression being $U V E R_{\text {meas }}$ the measured UVER value:

$$
\begin{aligned}
& U V E R_{313 D U}= \\
& \quad=\left[1-\frac{0.31(313-T O C)}{100}\right] U V E R_{\text {meas }} .
\end{aligned}
$$




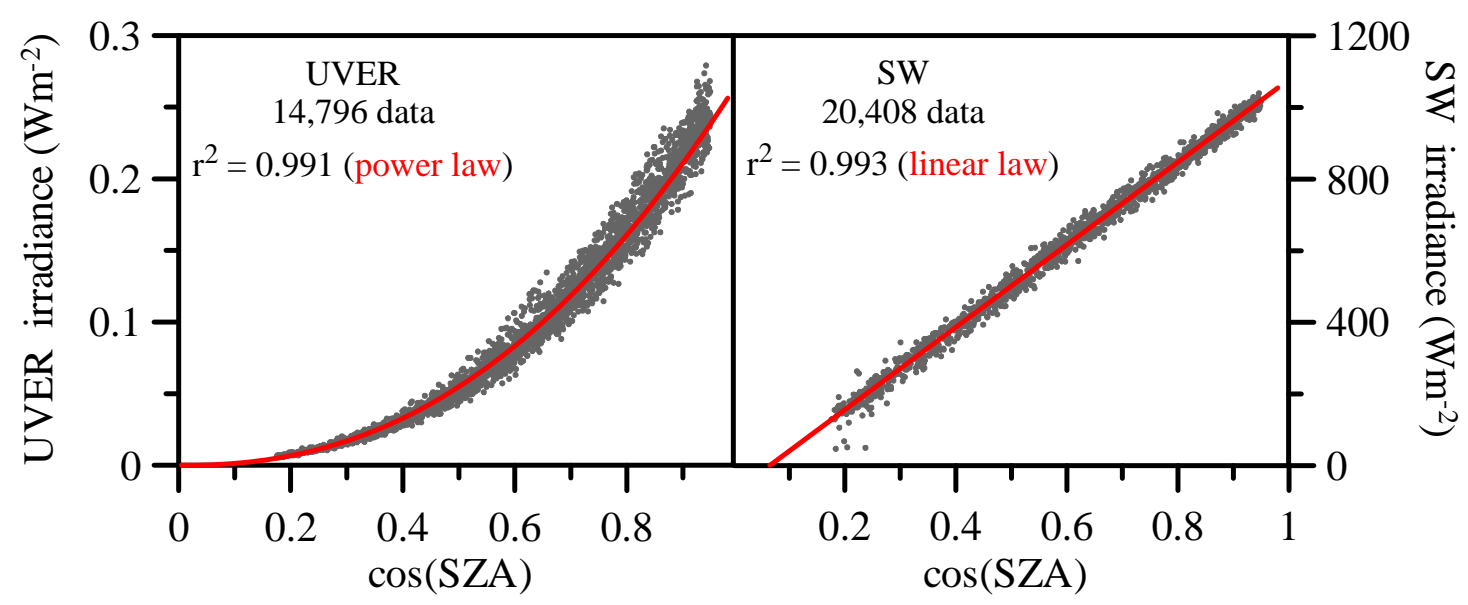

Fig. 1. UVER and SW irradiance under cloudless conditions as a function of the SZA cosine.

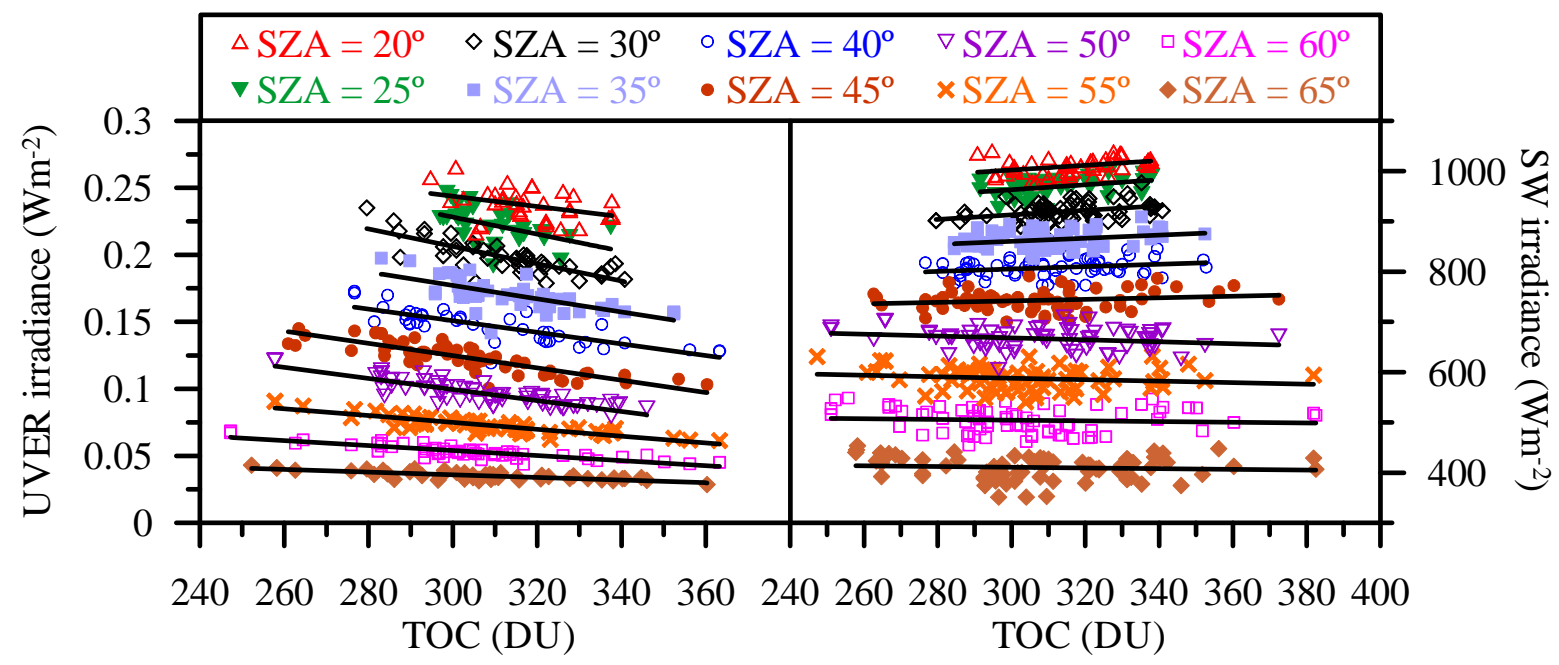

Fig. 2. UVER and SW irradiance under cloudless conditions as a function of TOC for different SZA.

Figure 3 shows the relationships between the SW irradiance and the hourly PWC for different SZA. The linear determination coefficients present values between 0.2 and 0.5 , and the average trend is $-3.36 \% \mathrm{~cm}^{-1}$. Changes in SW are statistically significant except for SZA $30^{\circ}$ and $40^{\circ}$. The dependence on SZA of the trend is higher than in the case of ozone effect on SW. The highest variation on PWC of SW occurs for high solar zenith angles (up to $-6 \% \mathrm{~cm}^{-1}$ ). The lowest variation appears for $\mathrm{SZA}=20^{\circ}$, and it takes a value around $-1.75 \% \mathrm{~cm}^{-1}$. UVER irradiance does not depend on PWC because the water vapour absorption band is not in the UV region. Hence, the UVER irradiance is not shown in Fig. 3.

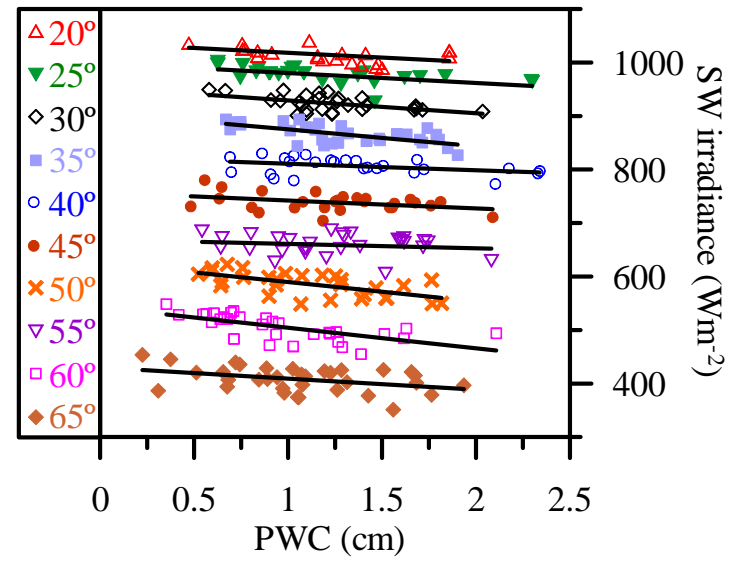

Fig. 3. SW irradiance under cloudless conditions as a function of PWC for different SZA. The number in the legend is SZA. 


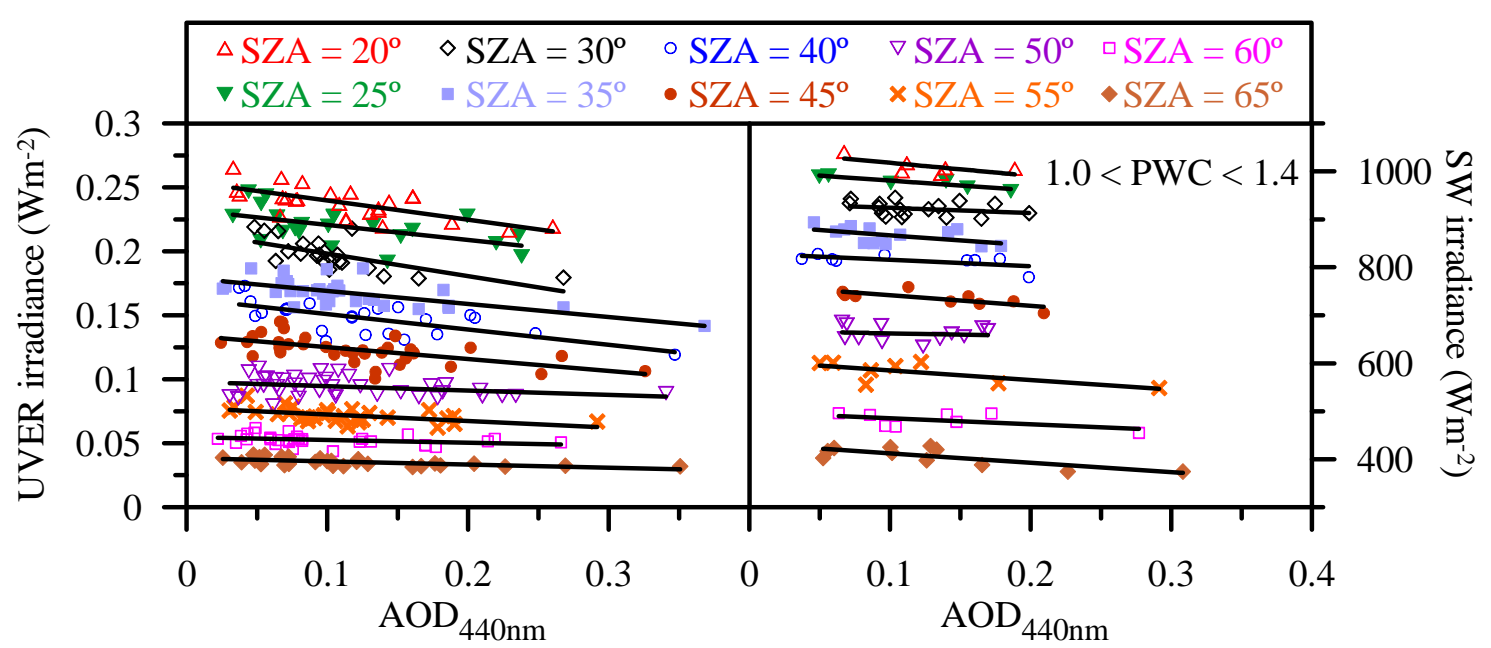

Fig. 4. UVER irradiance normalized to $313 \mathrm{DU}$, and SW irradiance under cloudless conditions as a function of AOD at $440 \mathrm{~nm}$ for different SZA.

Finally, the effect of aerosols on solar radiation was studied. UVER ${ }_{313 \mathrm{DU}}$ (using expression 2 to remove ozone effect) and SW irradiance (to remove the water vapour effect on SW, PWC was only considered between 1 and 1.4 $\mathrm{cm}$ ), are represented in Fig. 4 as a function of the hourly $\mathrm{AOD}_{440}$. A negative trend is shown for all SZA. In the UVER irradiance case, the determination coefficients of linear fit vary between 0.1 and 0.6 , and the trends show an average value of $-37 \%$ for $\mathrm{AOD}_{440}$ unity. In the SW irradiance case this percentage falls up to $28.4 \%$ for $\mathrm{AOD}_{440}$ unity, and the determination coefficients take values from 0.3 to 0.8 . The fits are not enough significant for the cases of $\mathrm{SZA}=50$ and $60^{\circ}$ in the UVER, and for SW when $\mathrm{SZA}=30$ and $50^{\circ}$. In conclusion, the effect of aerosols is stronger on the UVER irradiance than the SW one.

\section{Conclusions}

The dependence on astronomical and atmospheric factors of UVER and SW irradiance was quantified, and its statistical significance was tested and proved. UVER irradiance depends on SZA cosine by a power law, while SW one shows a linear trend. UVER is affected by ozone which reduces UVER levels around -0.31 $\% \mathrm{DU}^{-1}$, and by aerosols $\left(-28.4 \%\right.$ for $\mathrm{AOD}_{440}$ unity). The ozone effect on SW irradiance is negligible, but SW depends on water vapour $\left(\sim-3.36 \% \mathrm{~cm}^{-1}\right)$ and aerosols. The dependency on $\mathrm{AOD}_{440}$ is weaker than in the UVER case.

\section{Acknowledgements}

Financial supports from the Spanish MICINN (ref. CGL2009-08097/CLI, CGL2008-05939-C0300/CLI and CGL 2009-09740) and from the GR220 Project of the Junta de Castilla y León are gratefully acknowledged. The authors also thank the OMI International Science Team and the German Aerospace Centre (DLR) for the remote sensing ozone data. The authors would like to acknowledge the AERONET-PHOTONS-RIMA (http://aeronet.gsfc.nasa.gov) teams for the managements of these networks. 